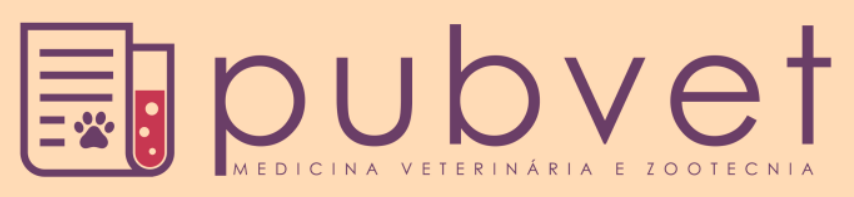

https://doi.org/10.31533/pubvet.v12n7a132.1-8

\title{
Osteopatia Craniomandibular Canina: Revisão
}

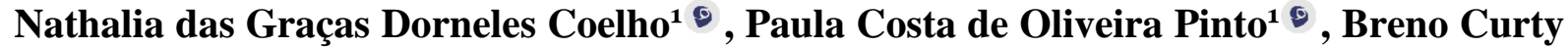 \\ Barbosa $^{2}{ }^{\circ}$, Fernanda dos Santos Alves ${ }^{\circ}$, Daniela Bastos de Souza Karam Rosa ${ }^{10}$, \\ Angélica da Costa Ferreira de Souza ${ }^{\bullet}$, Paloma Helena Sanches da Silva ${ }^{4}{ }^{\bullet}$, Sóstenes \\ Apolo Correia Marcelino ${ }^{\natural}$, Anelise Carvalho Nepomuceno ${ }^{3}{ }^{\ominus}$, Renato Cesar Sacchetto \\ Torres $^{30}$
}

${ }^{1}$ Mestranda do Departamento de Clínica e Cirurgia Veterinárias da Universidade Federal de Minas Gerais (UFMG). Belo Horizonte- MG Brasil.ndintensivismo@gmail.com paulacosta10@hotmail.com angelicacferreira@hotmail.com danibskr@gmail.com

${ }^{2}$ Doutorando do Departamento de Clínica e Cirurgia Veterinárias da Universidade Federal de Minas Gerais (UFMG). Belo Horizonte- MG Brasil.brenocurty@hotmail.com

${ }^{3}$ Professor da Universidade Federal de Minas Gerais (UFMG), Departamento de Clínica e Cirurgia veterinárias. Belo Horizonte-MG Brasil. rtorres@vet.ufmg.br anelise-imagem@vet.ufmg.br

${ }^{4}$ Residente em Clínica Cirúrgica em Animais de Companhia pela Universidade Federal de Minas Gerais (UFMG). Belo Horizonte- MG Brasil.palomahelena.vet@gmail.com sostenesmarcelino@hotmail.com

5 Médica veterinária intensivista- autônoma. Belo Horizonte-MG Brasil. fsalves.vet@ gmail.com

RESUMO. A osteopatia crânio mandibular (OCM) é uma afecção óssea rara de caráter degenerativo, osteopetrótico, autolimitante, não neoplásico, sem predileção sexual, que acomete cães na fase pré-púbere. As raças mais predispostas são as Terries em destaque para o West Highland White Terrier. Os sinais clínicos são variáveis dependendo dos ossos alterados e do grau de acometimento. Dentre os mais comuns estão febre, dor ao abrir a boca, aumento de volume da mandíbula, hiporexia e sialorreia. Os ossos do crânio são os mais acometidos, em especial, os mandibulares, os das articulações temporomandibulares e as bulas timpânicas. O diagnóstico se baseia nos achados clínicos, radiográficos e histopatológicos. As alterações radiográficas mais comuns são aumento da radiopacidade e volume das mandíbulas e das bulas timpânicas. O tratamento é sintomático, tendo como ponto principal o controle de dor e suporte nutricional. O prognóstico é heterogêneo. Os pacientes podem passar pela remissão completa da afecção ou serem submetidos à eutanásia por anquilose da articulação temporomandibular.

Palavras-chave: afecção óssea, canino, crânio, osteopetrose

\section{Canine Craniomandibular Osteopathy: Review}

\begin{abstract}
The mandibular cranial osteopathy (MCO) is a degenerative, osteopetrotic, self-limiting, non-neoplastic bone disorder, with no sexual predilection, which rarely affects dogs in the pre-pubertal stage. The most predisposed breeds are the Terries featured in the West Highland Terrier. The clinical signs are variable depending on the altered bones and degree of involvement. Among the most common are fever, mouth opening pain, jaw enlargement, hyporexia and sialorrhea. The bones of the skull are the most damaged, especially the mandibular, temporomandibular joints and tympanic sounds. The diagnosis of this condition is based on the clinical, histopathological and radiographic findings. The most radiographic changes are increased radiopacity and volume of mandibles and tympanic sounds. Its treatment is symptomatic, having as its main point pain control and nutritional support. The prognosis is heterogeneous. Patients may experience complete remission of the condition in weeks or undergo euthanasia due to ankylosis of the temporomandibular joint.
\end{abstract}


Keywords: bone affection, canine, skull, jaw

\section{Osteopatía Craneoomandibular Canina: Revisión}

RESUMEN. La osteopatía cráneo mandibular (OCM) es una afección ósea de carácter degenerativo, osteopetrótico, autolimitante, no neoplásico, sin predilección sexual, que afecta perros en la fase prepuberal. Las razas más predispuestas son las Terries en destaque para el West Highland White Terrier. Los signos clínicos son variables dependiendo de los huesos alterados y del grado de acometimiento. Comúnmente presenta fiebre, dolor al abrir la boca, aumento de volumen de la mandíbula, hiporexia y sialorrea. Los huesos del cráneo son los más afectados, en especial los mandibulares, los de las articulaciones temporomandibulares y las bullas timpánicas. El diagnóstico de esta aenfermedad se basa en los hallazgos clínico, histopatológico y radiográfico, siendo que este último muchas veces se muestra definitivo para ello. Las alteraciones radiográficas más comunes son aumento de la radiopacidad y volumen de las mandíbulas y de las bullas timpánicas. Su tratamiento es sintomático, teniendo como punto principal el control de dolor y soport nutricional. El pronóstico es heterogéneo. Los pacientes pueden pasar por la remisión completa de la afección o ser sometidos a la eutanasia por anquilosis de la articulación temporomandibular.

Palabras clave: afección ósea, canino, cráneo, mandíbula

\section{Introdução}

A osteopatia craniomandibular (OCM) é uma afecção óssea degenerativa, osteopetrótica, não neoplásica e geralmente autolimitante que acomete, eventualmente, cães (Padgett \& Mostosky, 1986). As sinonímias, um tanto quanto obsoletas, encontradas na literatura, são periostite mandibular e mandíbula de leão (Pool \& Leighton, $\underline{1969)}$.

A faixa etária mais atingida é a pré-púbere (Pool \& Leighton, 1969; Shorentein et al., 2014; Matiasovic et al., 2016). A predisposição racial é notória e entre as raças em evidência estão a West Highland White Terrier e Scottish Terrier (Macedo et al., 2015) e não há evidências de predileção sexual (Alexander \& Kallfelz, 1975).

A etiologia ainda não é bem esclarecida. Nas raças Terrier, infere-se que o tipo de herança seja autossômica recessiva (Padgett \& Mostosky, 1986). No entanto, nas raças não Terrier sugere-se a participação de infecções bacterianas (Escherichia coli) ou virais (vírus da Cinomose canina) (Watson et al., 1995).

Entre os ossos e articulações mais acometidos destacam-se as bulas timpânicas, os ramos das mandíbulas e as articulações temporomandibulares. Ocasionalmente, observam-se alterações em ossos chatos do crânio, como o occipital e temporal e em ossos longos (Alexander, 1983; Franch et al., 1998).
O diagnóstico definitivo é respaldado nos sinais clínicos, achados radiográficos e exame histopatológico. Dentre os sinais clínicos destacam-se a dor persistente na região de articulação temporomandibular, aumento de volume da mandíbula, hiporexia, sialorreia e febre intermitente (Varalho et al., 2012; Macedo et al., 2015; Matiasovic et al., 2016).

Os achados radiográficos comumente encontrados são: aumento bilateral e simétrico da radiopacidade óssea e da espessura dos ramos da mandíbula e bula timpânica (Alexander, 1983; Huchkowsky, 2002). No que diz respeito aos achados histológicos, o espessamento generalizado das trabéculas ósseas é o mais observado (Alexander, 1983).

O tratamento é sintomático e baseia-se especialmente no controle da dor. A ação antiálgica é alcançada por anti-inflamatórios não esteroidais, porém algumas vezes usa-se a associação com analgésicos estritos, dentre eles destaca-se o cloridrato de tramadol (Huchkowsky, 2002; Varalho et al., 2012; Shorentein et al., 2014). O prognóstico é variável, visto que, cães podem apresentar diferentes ossos do crânio envolvidos com distintos graus de acometimento (Alexander, 1983).

A presente revisão ao compilar informações a respeito da etiologia, da epidemiologia, dos aspectos clínicos, radiográficos, histopatológicos e terapêuticos da OCM canina tem por objetivo 
facilitar o reconhecimento e abordagem desta afecção na clínica médica de pequenos animais.

\section{Revisão de literatura}

A OCM é uma afecção óssea definida como osteoproliferativa, degenerativa, não neoplásica, autolimitante, sem predileção sexual, que acomete, eventualmente, cães (Padgett \& Mostosky, 1986). O primeiro relato dessa afecção data da década de 50, sendo diagnosticada em cinco West Higland White Terrier não aparentados (Littlewort, 1958), e desde então tem sido frequentemente reconhecida nesta raça e, esporadicamente, em cães não Terrier (Franch et al., 1998).

Os cães atingidos estão em fase de crescimento, em especial na fase pré-púbere, sendo que a faixa etária mais acometida situa-se entre o terceiro e oitavo mês de idade (Pool \& Leighton, 1969; Shorentein et al., 2014; Matiasovic et al., 2016).

A predisposição racial é notória, entre as raças em evidência estão a West Highland White Terrier (Macedo et al., 2015), e Scottish Terrier (Shorentein et al., 2014). Não há evidências de predileção sexual (Alexander \& Kallfelz, 1975). Dentre as raças não Terries relatadas esporadicamente pode-se citar o Cão dos Pirinéus (Franch et al., 1998), Dobermann e Pastor alemão (Watson et al., 1995); Bullmastiff (Huchkowsky, 2002), Akita (Ratterree et al., 2011) e Bull Dog Inglês (Varalho et al., 2012)

A etiologia da OCM ainda não está bem esclarecida. Ocorre em poucas raças de cães e, geralmente, entre indivíduos aparentados. Portanto, infere-se que seja proveniente de uma herança autossômica entre as raças frequentemente afetada (Alexander, 1983; Padgett \& Mostosky, 1986). Estudos realizados na década de 70 e 80, por Padgett \& Mostosky (1986) trouxeram mais informações a respeito do modo de herança nas raças West Higland White Terrier, o definindo como uma herança autossômica recessiva (Padgett \& Mostosky, 1986).

Nas raças não Terrier sugere-se que a etiologia seja infeciosa e não hereditária, acreditando-se na participação de agentes bacterianos (Escherichia coli) ou virais (vírus da Cinomose canina) na gênese da doença. Quanto à cinomose sugere-se que a infecção cause OCM sem causar sinais clínicos clássicos associados às infecções por vírus (Watson et al., 1995; Munjar et al., 1998). Tal dedução faz com que a etiologia da OCM em não Terries se assemelhe a doença de Padgett em humanos, pois há evidências crescentes que esteja associada a infecções virais (Isselbacher et al., 1980).

Os ossos e articulações mais afetados são o occipital, bula timpânica, osso temporal, ramo da mandíbula, arco do zigomático e articulação temporomandibular. No entanto, ocasionalmente, observam-se alterações em ossos longos e demais ossos do crânio como: frontal, parietal, tentório cerebelar, lacrimais e maxilares. Dentre os ossos que mais se destacam estão os da mandíbula e bulas timpânicas. Observa-se uma frequência de acometimento de ambos em $50 \%$ dos pacientes e de $33 \%$ e $13 \%$, respectivamente, da mandíbula e bula timpânica isoladamente (Alexander, 1983; Franch et al., 1998; Huchkowsky, 2002).

O estágio de proliferação óssea na OCM varia entre os pacientes de dias a semanas. Durante essa fase osteopetrótica é que surgem os diversos sinais clínicos (Alexander, 1983). Os mais observados estão diretamente associados à intensidade da agressão óssea e a localização da injúria, podendo variar desde uma proliferação discreta dos ossos da mandíbula até casos de envolvimento da bula timpânica e articulação temporomandibular. Essa última, quando afetada, pode sofrer anquilose entre os processos angulares da mandíbula e as bulas timpânicas. A alteração biomecânica da articulação temporomandibular culmina na separação milimétrica entre a superfície oclusal dos dentes e até mesmo na incapacidade completa em abrir a boca (Alexander, 1983; Ratterree et al., 2011).

Dentre os sinais clínicos estão a dor constante e hipertermia intermitente, dor a abertura da boca e ao toque da mandíbula ou maxila, prostração, sialorreia, inchaço bilateral da mandíbula, halitose, dificuldade de ingerir alimentos sólidos, emaciação e até mesmo dor cervical isoladamente (Alexander, 1983; Ratterree et al., 2011; Macedo et al., 2015; Matiasovic et al., 2016).

As alterações ósseas no esqueleto apendicular são incomuns, principalmente nas raças Terries. No entanto, no caso de acometimento dos ossos longos, pode ser observada claudicação (Franch et al., 1998; Huchkowsky, 2002). Em quadros ainda mais raros, há relatos de déficits neurológicos graves secundários ao espessamento intenso dos ossos do calvário com compressão cerebelar e do 
tronco encefálico que levaram o paciente a óbito (Ratterree et al., 2011).

Tal variedade de manifestações clínicas deve trazer ao médico veterinário uma necessidade de entender melhor a etiologia, epidemiologia e os métodos diagnósticos. A precocidade no reconhecimento da doença melhora o prognóstico, uma vez que a dor à palpação da mandíbula, aumento de volume em seus ramos e dificuldade ao abrir a boca podem não ser observados (Varalho et al., 2012; Shorentein et al., 2014).

Frente aos exames radiográficos e laboratoriais, os analítos avaliados na bioquímica sérica, hemograma e perfil urinário dos pacientes portadores da OCM podem apresentar-se na normalidade ou com alterações associadas à anorexia e ou aumento da atividade óssea. Dentre os problemas passíveis de serem encontradas estão leucocitose neutrofílica com desvio a direita (leucograma de estresse causado pelo constante e intenso quadro álgico) (Franch et al., 1998), hiperfosfatemia (Ratterree et al., 2011), aumento dos compostos uréicos do sangue, possivelmente causado pela desidratação associada à anorexia e oligodipsia (Franch et al., 1998), elevação da fosfatase alcalina associada ao aumento da atividade osteoblástica (Huchkowsky, 2002; Ratterree et al., 2011) e hipoalbuminemia discreta (Franch et al., 1998; Huchkowsky, 2002; Ratterree et al., 2011).

O aspecto radiográfico dos ossos do crânio nas diferentes projeções é característico da OCM, permitindo o diagnóstico definitivo apenas pela avaliação radiográfica das regiões possivelmente afetadas em associação com dados da anamnese e achados clínicos (Franch et al., 1998; Alexander, 1983). As projeções mais indicadas são as laterolaterais direita e esquerda e, se necessário, realizar projeções radiografias oblíquas laterais (Alexander, 1983; Shorentein et al., 2014; Macedo et al., 2015) e ventro-dorsal (Varallho et al., 2012; Shorentein et al., 2014) do crânio (Figura. 1).

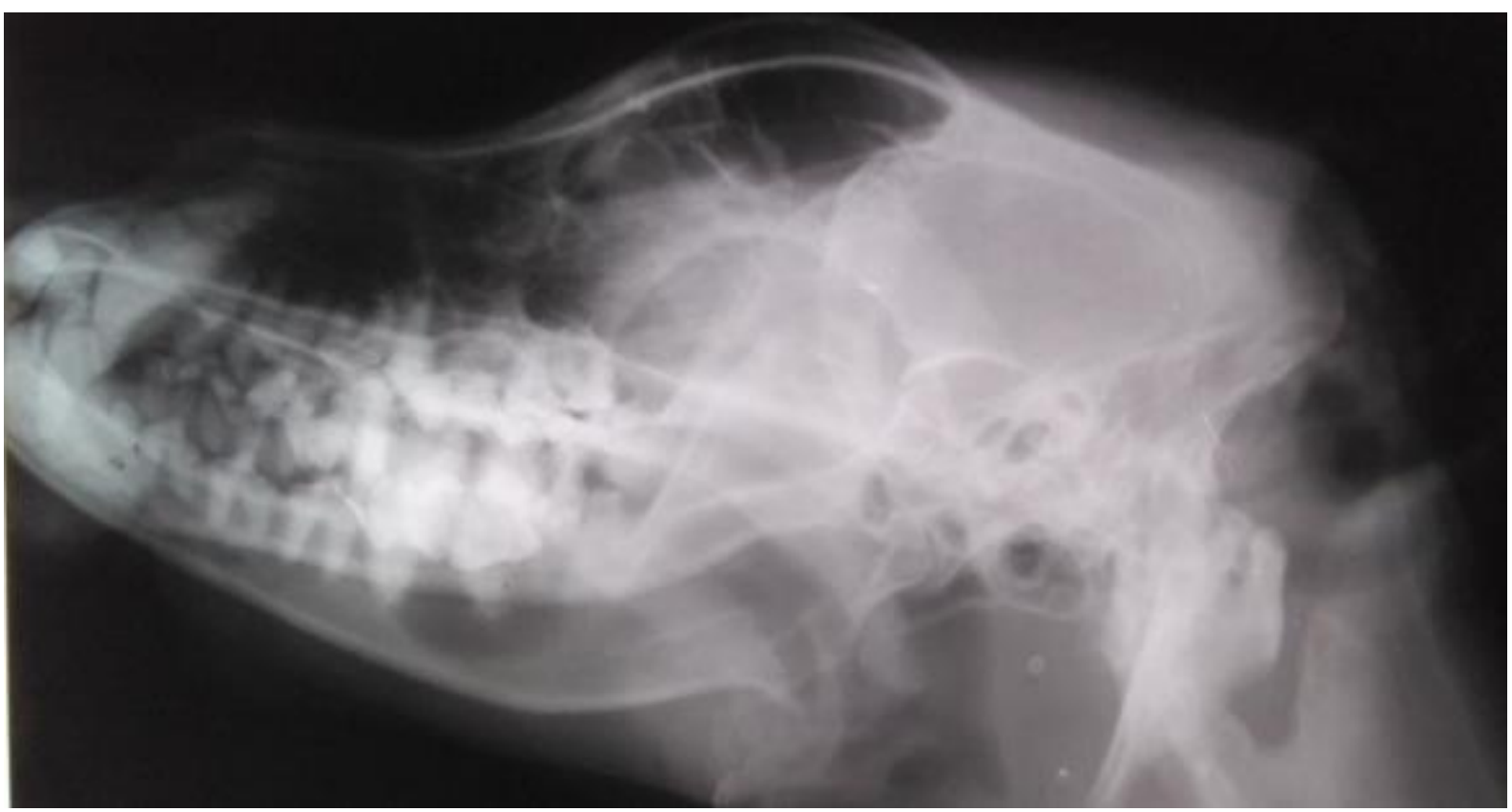

Figura 1. Radiografia oblíqua lateral direita do crânio de um cão, fêmea, 120 meses, sem raça definida, cuja aparência radiográfica está normal.

As projeções radiográficas supracitadas quando realizadas em associação permitem uma avaliação em profundidade das estruturas acometidas. Dessa forma, as proliferações ósseas densas que se projetam da superfície periosteal dos ossos laterais e ventro-dorsais da calota craniana são facilmente observados (Alexander, 1983; Huchkowsky, 2002) (Figura. 2).

As características da distribuição e da gravidade das alterações ósseas, possivelmente, variam entre as raças. Porém, de uma maneira geral, as deformações causadas pela proliferação óssea periosteal mais encontradas na OCM são: aumento da radiopacidade e volume da mandíbula, principalmente na região ventral do ramo horizontal e ou maxila, com desaparecimento dos limites entre as raízes dos dentes e ossos alveolares e destes com as estruturas adjacentes. Juntamente do aumento de volume e radiopacidade da bula timpânica e do 
osso temporal, assim como da articulação temporomandibular (Padgett \& Mostosky, 1986;

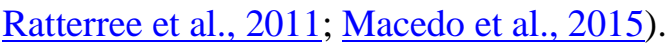

Existe uma diferença marcante na distribuição das lesões ósseas entre cães Terries e os não Terries, sendo observado, com frequência, nos primeiros um envolvimento da articulação temporomandibular em associação a outros ossos do crânio. Por sua vez, nos não Terries percebe-se o acometimento isolado da mandíbula, em especial na parte horizontal, sendo rara a presença de danos à articulação temporomandibular (Riser et al., 1967; Franch et al., 1998; Huchkowsky, 2002).

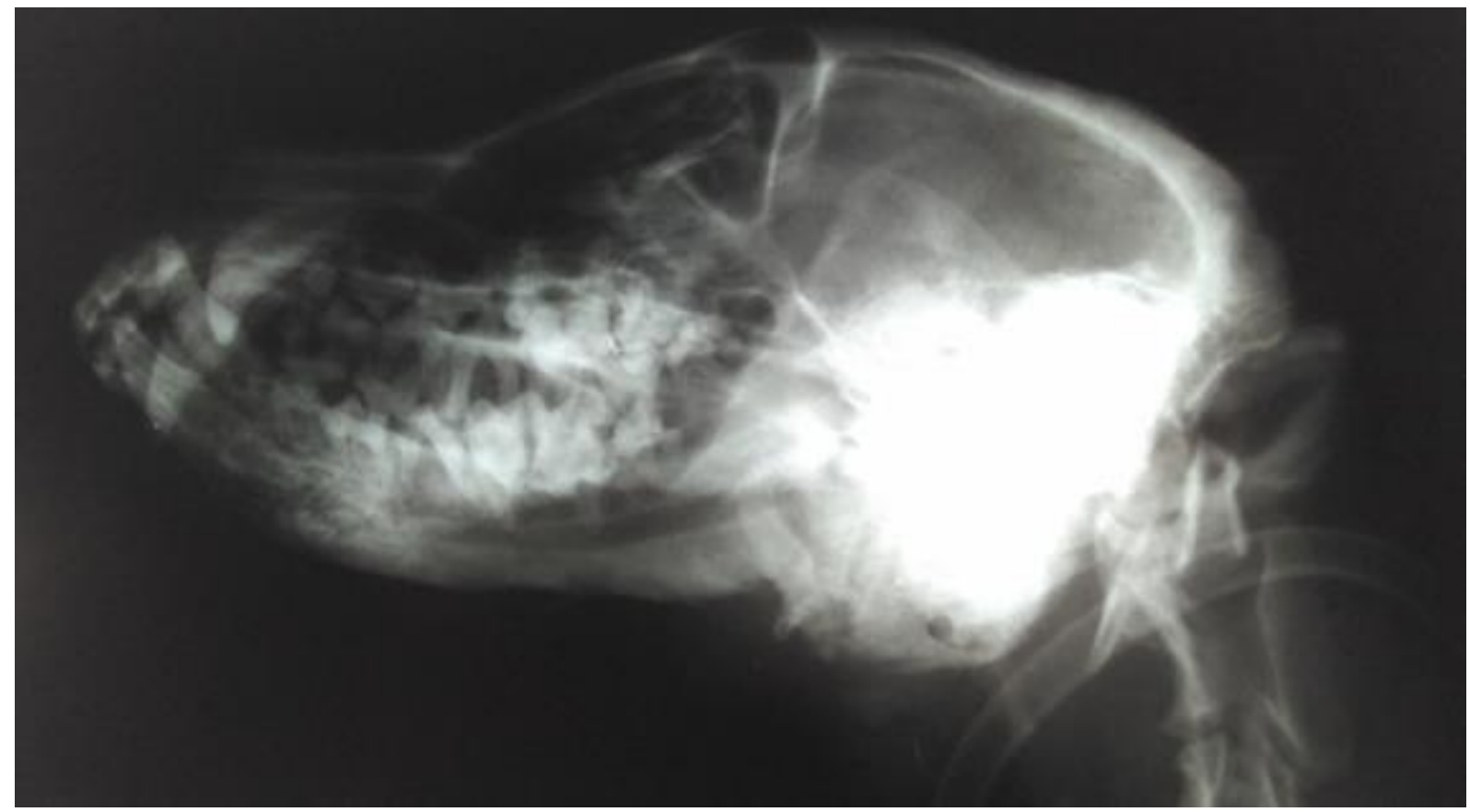

Figura 2. Radiografia latero-lateral direita do crânio de um cão, Scottsh Terrier, macho, 12 meses, com histórico de dificuldade em abrir a boca e sialorreia, há 30 dias. Visibiliza-se intenso aumento de radiopacidade (osteopretrose) nas regiões correspondentes a articulação temporo mandibular e a bula timpânica.

Apesar do comportamento da doença achados radiográficos não são convencionais. apresentar lesões ósseas semelhantes, porém com Dentre esses observam-se uma mineralização diferentes ossos e graus de acometimento, os intensa, bilateral, simétrica, restrito às bulas médicos veterinários devem estar preparados para timpânicas, sem acometimento claro das estruturas suspeitar da OCM mesmo em casos no qual os adjacentes (Shorentein et al., 2014) (Figura.3).

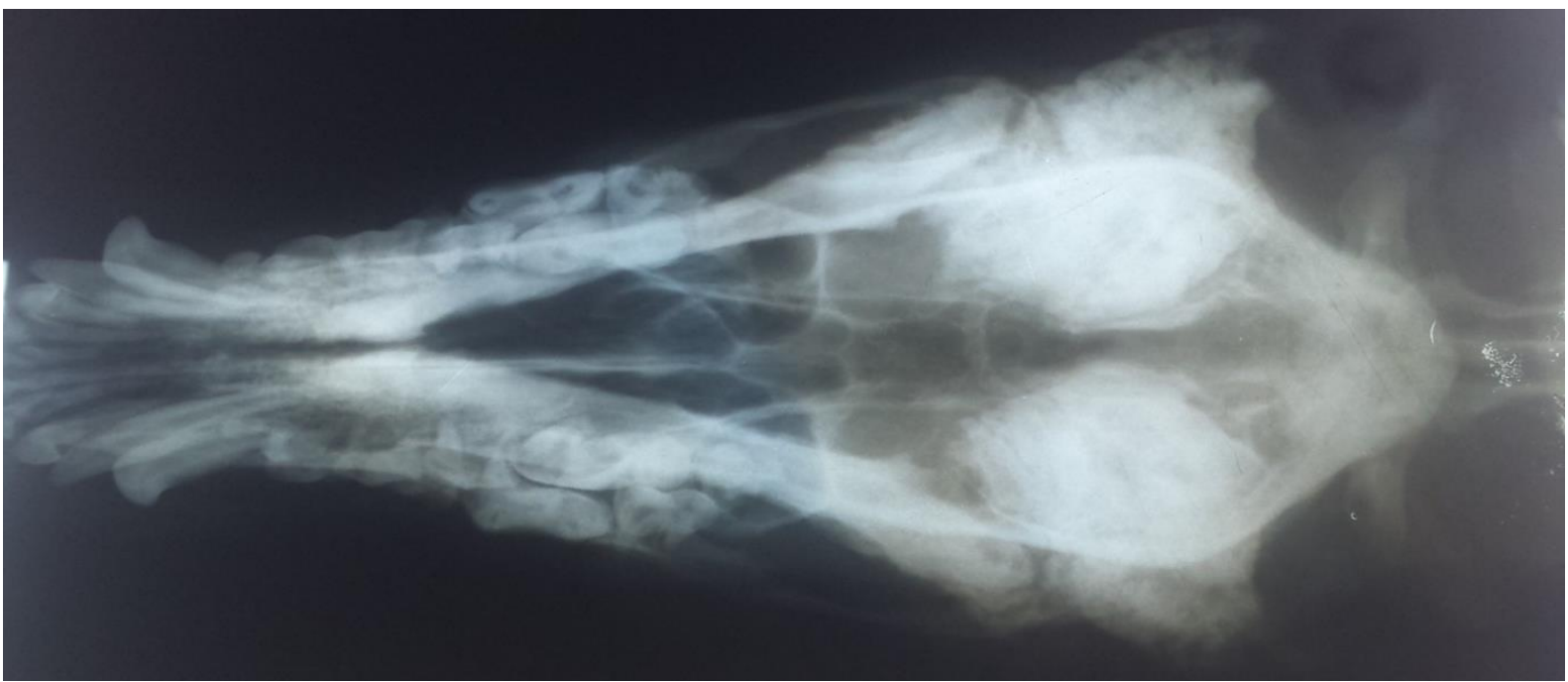

Figura 3. Radiografia ventro-dorsal do crânio de um cão, Scottsh Terrier, macho, 12 meses, com histórico de dificuldade de abrir a boca e sialorréia há 30 dias. Visibiliza-se intenso aumento de radiopacidade (osteopretrose) na região correspondente a articulação temporo mandibular, simétrico e bilateral. 
As alterações osteopetróticas observadas na OCM estão na maior parte dos casos restritas aos ossos do crânio. No entanto, podem-se observar ocasionalmente em cães não Terries danos ao esqueleto apendicular, como o aumento da radiopacidade e alargamento das regiões metafisárias e em menor frequência o espessamento endosteal e bilateral dos fêmures e dos ílios (Franch et al., 1998; Ratterree et al., 2011).

O exame radiográfico é o melhor método para diagnóstico, estadiamento, avaliação do curso e possível prognóstico dessa afecção. Em alguns casos, se houver envolvimento da articulação temporomandibular ou estruturas adjacentes difíceis de serem visibilizadas nas radiografias, pode ser feita tomografia computadorizada do crânio (Shorentein et al., 2014; Matiasovic et al., $\underline{2016)}$.

A biopsia para coleta de amostras destinadas ao histopatológico geralmente não é necessária, visto que as alterações radiográficas são características da afecção. No entanto, quando realizada, se obtém o diagnóstico definitivo, pois a osteomegalia ou osteopetrose observadas em lâminas também são características da afecção (Shorentein et al., 2014).

Os achados histológicos da OCM são compatíveis com muito tecido ósseo por unidade de volume do osso como órgão. Essa alteração pode se causada por menor reabsorção (Figura 4) ou por maior aposição ósseas (Santos \& Alessi, 2016).

Comumente observam-se o espessamento generalizado e coalescência das abundantes trabéculas ósseas com aumento das linhas de cimentação óssea, então faz com que o material analisado apresente um padrão em mosaico devido às linhas de matriz óssea acumuladas entre os ossos lamelares (Figura 4) (Alexander, 1983; Santos \& Alessi, 2016). O mecanismo causador da osteopetrose de origem genética é a falha no processo de reabsorção óssea, caracterizado pela redução ou ausência da osteólise osteocítica, observando-se osteocítos pequenos com perda da basofília e por vezes ausentes (Santos \& Alessi, 2016).

A acentuada proliferação óssea pode ter como consequência alguns pontos de osteonecrose. Essa alteração é resultante da morte do osteócito, a célula responsável pela manutenção do tecido ósseo como tecido vivo. Dentre as alterações observadas no osso necrótico estão à presença de trabéculas ósseas com lacunas vazias e por vezes fragmentadas e com alterações das propriedades tintoriais (Santos \& Alessi, 2016).

Quando a área de espessamento ósseo está localizada na porção ventral dos corpos mandibulares, observa-se ao histopatológico uma rede de trabéculas ósseas compostas por matriz condroide em diferentes graus de mineralização. $\mathrm{O}$ eixo longo as trabéculas ósseas se dispõem perpendiculares ao eixo longo da cortical da mandíbula. Quanto mais próximas da mandíbula essas trabéculas estão mais mineralizado está o tecido condroide. As corticais dos ossos do crânio também podem estar afetadas, perdendo sua característica compacta lamelar, sendo observadas as trabéculas ósseas mais espalhadas quando comparadas a mesma região de um cão hígido e de faixa etária semelhante (Franch et al., 1998).

No exame histopatológico as células inflamatórias podem estar presentes ou não no material amostrado (Alexander, 1983). Quando observadas podem estar distribuídas, nos espaços medulares, em poucos focos densos (predominantemente neutrófilos, linfócitos e células plasmáticas) (Huchkowsky, 2002). Numerosos fibroblastos, osteoclastos e osteoblastos podem estar presentes ao redor das trabéculas ósseas, abundantes, espessas e irregulares (Varalho et al., 2012. Macedo et al., 2015; Matiasovic et al., 2016).

O diagnóstico definitivo da OCM geralmente é obtido pela associação dos achados clínicos e epidemiológicos, avaliação radiográfica dos ossos do crânio e, quando viável, o exame histopatológico (Padgett \& Mostosky, 1986; Franch et al.,1998). Entre os diagnósticos diferenciais para OCM estão a osteomielite, periostite traumática, distúrbios metabólicos (hiperparatireoidismo), neoplasias (osteossarcomas e fibrossarcomas), síndromes hiperostóticas (Huchkowsky, 2002) e osteoatrites (Chantaracherd et al., 2015) .

Deve-se atentar para os diagnósticos diferencias na OCM tanto pela similaridade clínica, quanto histopatológica e radiográfica. Há neoplasias de fácil confundimento, como os fibrossarcomas, que podem apresentar intensa presença de fibroblastos sem alterações neoplásicas. Nesses casos, a imunoistoquímica pode definir precisamente qual a afecção (Varalho et al., 2012). 


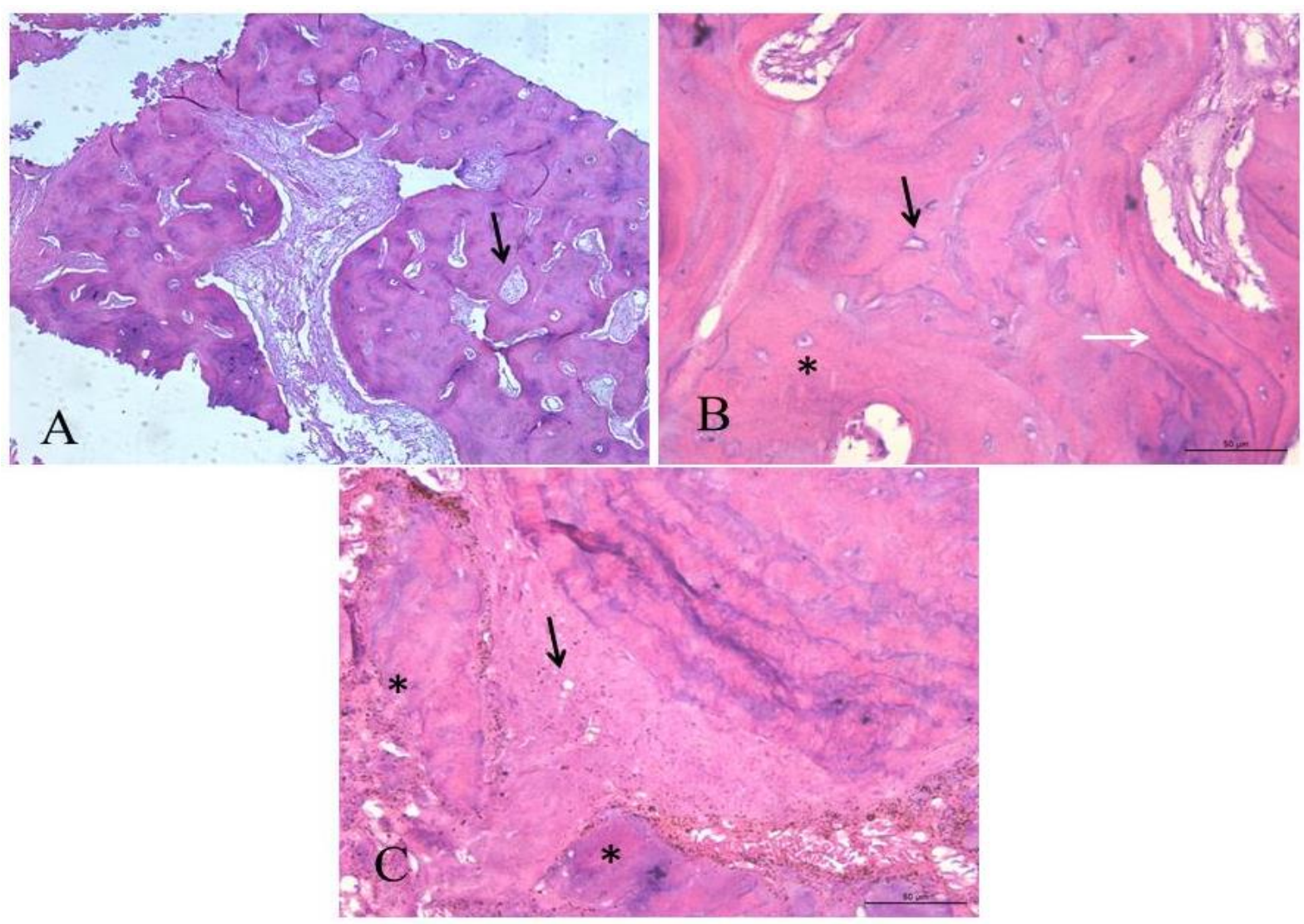

Figura 4. Exame histopatológico de fragmento ósseo do ramo ventral da mandíbula de um cão, Scottsh Terrier, macho, 12 meses, com histórico de dificuldade de abrir a boca e sialorreia há 30 dias. A: Intenso espessamento das trabéculas ósseas assumindo arranjo osteônico (seta). B: Osteócitos diminuídos com núcleos picnóticos (asterisco) e, por vezes, ausentes (seta preta). Aumento das linhas de cimentação óssea (seta branca). C: Trabéculas ósseas com lacunas vazias (seta) por vezes fragmentadas e com alteração das propriedades tintoriais (osteonecrose) (asterisco). Fonte: Arquivo cedido pela Setor de Patologia Animal - UFMG.

Embora a condição da OCM não acarrete em mortalidade diretamente, a não realização do tratamento suporte e sintomático do paciente pode levar a anorexia e oligodipsia. Estas alterações acarretam desequilíbrios hídricos, eletrolíticos e retenção de catabólitos que poderão levar ao óbito do paciente (Alexander, 1983; Franch et al., 1998).

O tratamento sintomático se baseia no controle da dor. A ação anti-algica é atingida por antiinflamatórios não esteroidais (Shorentein et al., 2014), ou esteroidais, como a prednisolona (Franch et al., 1998). O tratamento com AINES geralmente é prolongado, podendo estender por mais de cinco dias (Varalho et al., 2012) até um mês para o meloxicam $(0,1 \mathrm{mg} / \mathrm{kg})$ (Huchkowsky, 2002) ou até 10 dias, quando optado por carproflan $(2,2 \mathrm{mg} / \mathrm{kg}$ ) (Macedo et al., 2015). No entanto, algumas vezes é preciso a associação multimodal de fármacos a analgésicos estritos, dentre eles destaca-se o cloridrato de tramadol $(4 \mathrm{mg} / \mathrm{kg})$ e dipirona $(25 \mathrm{mg} / \mathrm{kg})$, na busca por potencializar o efeito analgésico do protocolo convencional (Varalho et al., 2012; Macedo et al., 2015).

De acordo com a gravidade de cada paciente pode ser necessária a associação da fluidoterapia e nutrição parenteral, tendo como opções as sondas nasogástrica e esofágica para o manejo nutricional (Franch et al., 1998). Por vezes, o tratamento é prolongado (1-2 meses) ou até que o cão chegue à maturidade sexual e ocorra a resolução espontânea da proliferação óssea. Em alguns casos, é realizada a castração na tentativa de acelerar a melhora do paciente (Huchkowsky, 2002; Varalho et al., 2012; Macedo et al., 2015).

O prognóstico é variável, pois os cães podem apresentar diferentes ossos do crânio envolvidos com distintos graus de acometimento (Alexander, 1983). Há casos extremos em que os pacientes são submetidos à eutanásia devido ao envolvimento acentuado dos ossos da região temporomandibular, inclusive com anquilose, que promove dor intensa e/ou incapacidade de abrir a 
cavidade oral (Alexander, 1983; Franch et al., 1998; Ratterree et al., 2011).

\section{Considerações finais}

A OCM deve ser incluída nos diagnósticos diferenciais de cães apesar de ser uma afecção rara. Nos Terries o caráter autossômico recessivo é determinante para não permitir a reprodução entre animais que tenham apresentado esta alteração. A OCM pode acometer diferentes ossos, em variados graus de lesão, portanto, o prognóstico dos cães é variável.

\section{Referências bibliográficas}

Alexander, J. W. 1983. Selected Skeletal Dysplasias: Craniomandibular Osteopathy, Multiple Cartilaginous Exostoses, and Hypertrophic Osteodystrophy. Veterinary Clinics of North America: Small Animal Practice, 13(1), 55-70.

Alexander, J. W. \& Kallfelz, F. A. 1975. A case of craniomandibular osteopathy in a Labrador Retriever. Journal of the American Animal Hospital Association, 70, p. 560-563.

Chantaracherd, P., John, M. T. \& Schiffman, E. L. 2015. Temporomandibular Joint Disorders Impact on Pain, Function, and Disability. JDR Clinical \& Translational Research, 20(10), 1585.

Franch, J., Cesari, J. R. \& Font, J. 1998. Craniomandibular osteopathy in two Pyrenean mountain dogs. Veterinary Record, 142, 455459.

Huchkowsky, S. L. 2002. Craniomandibular osteopathy in a bullmastiff. Canadian Veterinary Journal, 43, 883- 885.

Isselbacher, K. J., Adams, R. D., Braunwalde, Pertersdorf, R. G. \& Wilson, J. D. 1980. Harrison's Principles of Internal Medicine (1890 p.). Mc Graw-Hill Book Co, New York, USA.

Littlewort, M. C. G. 1958. Comparison of risk factors for hypertrophic osteodystrophy, craniomandibular osteopathy and canine distemper virus infection. Veterinary Record, 11(70), 37-43.

Macedo, A. S., Casagrande, A. J., Friesen, R., \& Minto, B.W. 2015. Craniomandibular Osteopathy in a West Highland White Terrier. Acta Scientiae Veterinariae, 43(1), 1- 4.

Matiasovic, M., Caine, A., Scarpante, E. \& Cherubini, G. B. 2016. Imaging Diagnosis -
Magnetic Resonance Imaging Features of Craniomandibular Osteopathy in an Airedale Terrier. Veterinary Radiology \& Ultrasound, 57(3), 27-29.

Munjar, T. A., Austin, C. A. \& Breur, G. J. 1998. Comparison of risk factors for hypertrophic osteodystrophy, craniomandibular osteopathy and canine distemper virus infection. Veterinary and Comparative Orthopaedics and Traumatology, 11, 37-43.

Padgett, A. G. \& Mostosky, U. V. 1986. Animal Model: The Mode of Inheritance of Craniomandibular Osteopathy in West Highland White Terrier Dogs. American Journal of Medical Genetics, 25, 9-13, 1986.

Pool, R. R. \& Leighton, R. L. Craniomandibular osteopathy in a dog. 1969. Journal of the American Veterinary Medical Association, 154, 657-660.

Ratterree, W. O., Glassman, M. M., Driskell, E. A. \& Having, M. E. 2011. Craniomandibular Osteopathy with a Unique Neurological Manifestation in a Young Akita. Journal of the American Animal Hospital Association, 47, 712.

Riser, W. H., Parkes, L. J. \& Shirer, J. F. 1967. Canine craniomandibular osteopathy. Veterinary Radiology \& Ultrasound, 8, 23-30.

Santos, R. L. \& Alessi, A. C. 2016. Patologia Veterinária ( $2^{\mathrm{a}}$ ed.). Roca, Rio de Janeiro, BR.

Shorentein, B., Schwartz, P. \& Kross, P. H. 2014. Craniomandibular osteopathy in dogs. Veterinary Medicine Today What Is Your Diagnosis, 245(5), 41-42.

Varalho, G. R., Lima, B. R., Raposo, T. M. M. \& Daleck, C. R. 2012. Osteopatia Crânio mandibular em Bulldog Inglês. Relato de Caso. Ars Veterinaria, 28(4), 218-221.

Watson, A. D. J., Adams, W. M. \& Thomas, C. 1995. Craniomandibular osteopathy in dogs. Compendium on continuing education for the practicing veterinarian., 17, 911-922.

Recebido: 9 abr. 2018.

Aprovado: 27 abr. 2018

Publicado: 10 jul. 2018

Licenciamento: Este artigo é publicado na modalidade Acesso Aberto sob a licença Creative Commons Atribuição 4.0 (CC-BY 4.0), a qual permite uso irrestrito, distribuição, reprodução em qualquer meio, desde que o autor e a fonte sejam devidamente creditados. 